Artículos Científicos

\title{
¿Es posible una soberanía alimentaria en México?
}

Is a Food Sovereignty Possible in Mexico?

A soberania alimentar é possível no México?

José Luis Carmona Silva

El Colegio de Tlaxcala A. C., México joseluiscs@coltlax.edu.mx https://orcid.org/0000-0002-0858-2792

Lizbeth Sánchez Flores

Benemérita Universidad Autónoma de Puebla, México

lisanflo@yahoo.com.mx https://orcid.org/0000-0003-1318-3873

José Aurelio Cruz De los Ángeles

Benemérita Universidad Autónoma de Puebla, México pepejac52@yahoo.com.mx https://orcid.org/0000-0002-8682-366X 


\section{Revista Iberoamericana \\ de las Ciencias Sociales y \\ Humanísticas}

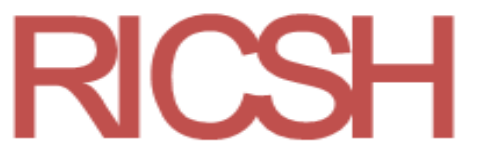

ISSN: $2395-7972$

\section{Resumen}

El objetivo de este trabajo es analizar el concepto de soberanía alimentaria, así como determinar si la soberanía alimentaria en México puede considerarse como una realidad, una posibilidad o es una quimera. La metodología empleada en este trabajo es eminentemente cualitativa. En primer lugar, se realizó una revisión documental acerca del concepto ya mencionado y una revisión histórica de este. En segundo, se revisó el estado que guarda la alimentación y producción de alimentos en México y se analizó la posibilidad de ejercer una verdadera soberanía alimentaria. En los resultados se observa que a través del tiempo nuestro país ha ido perdiendo su soberanía alimentaria, y dadas las circunstancias actuales, por el momento parece muy complicado que pudiera ser una realidad. Por un lado, la población ocupada en el sector primario ha sufrido un drástico cambio: de $58.32 \%$ del total en 1950 a solo $12.6 \%$ en el año 2019, lo que dificulta totalmente la producción de alimentos; por otra parte, las políticas alimentarias actuales en materia de alimentación tampoco ayudan en este sentido, pues actualmente se pretende garantizar la alimentación de la población a través de la compra masiva de alimentos de cualquier parte del mundo, donde sea más barato, apoyando también solo la producción de la agroindustria de las empresas transnacionales, en lugar de apoyar el campo mexicano y reactivar la producción de autoconsumo.

Palabras clave: agroindustria, políticas alimentarias, sector primario, soberanía alimentaria.

\section{Abstract}

The objective of this work is to analyze the concept of food sovereignty, as well as determining if food sovereignty in Mexico can be considered as a reality, a possibility or a chimera. The methodology used in this work is eminently qualitative. First, a documentary review was carried out about the concept of food sovereignty, a historical review of it was carried out. Secondly, the state of food nutrition and food production in Mexico was reviewed and the possibility of exercising true food sovereignty was analyzed. The results show that over time our country has been losing its food sovereignty, and given the current circumstances at the moment, it seems very complicated that it could be a reality. On the one hand, the population employed in the primary sector has undergone a drastic change, going from $58.32 \%$ of the total in 1950 to just $12.6 \%$ in 2019, which makes food production totally difficult; on the other hand, current food policies in terms of food do not help in this regard 


\section{Revista Iberoamericana \\ de las Ciencias Sociales y \\ Humanísticas}

ISSN: $2395-7972$

either, since currently the aim is to guarantee the food of the population through the massive purchase of food from any part of the world, where it is cheaper, also supporting only the production of the agro-industry of the transnational companies, instead of support the Mexican countryside and reactivate the production of self-consumption.

Keywords: agribusiness, food policies, primary sector, food sovereignty.

\section{Resumo}

O objetivo deste trabalho é analisar o conceito de soberania alimentar, bem como determinar se a soberania alimentar no México pode ser considerada uma realidade, uma possibilidade ou uma quimera. A metodologia utilizada neste trabalho é eminentemente qualitativa. Primeiro, foi realizada uma revisão documental do conceito acima mencionado e uma revisão histórica do mesmo. Segundo, o estado da produção de alimentos e alimentos no México foi revisto e a possibilidade de exercer verdadeira soberania alimentar foi analisada. Os resultados mostram que, com o tempo, nosso país perdeu sua soberania alimentar e, dadas as circunstâncias atuais, no momento parece muito complicado que isso possa ser uma realidade. Por um lado, a população empregada no setor primário sofreu uma mudança drástica: de 58,32\% do total em 1950 para apenas 12,6\% em 2019, o que dificulta totalmente a produção de alimentos; Por outro lado, as atuais políticas alimentares na área de alimentos também não ajudam nesse aspecto, pois atualmente se destina a garantir os alimentos da população através da compra massiva de alimentos de qualquer lugar do mundo, onde seja mais barato, apoiando apenas a produção da agroindústria das empresas transnacionais, em vez de apoiar o campo mexicano e reativar a produção do autoconsumo.

Palavras-chave: agronegócio, políticas alimentares, setor primário, soberania alimentar. Fecha Recepción: Febrero 2020 Fecha Aceptación: Julio 2020 


\section{Revista Iberoamericana \\ de las Ciencias Sociales y \\ Humanísticas}

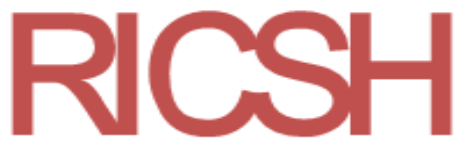

ISSN: $2395-7972$

\section{Introducción}

Vivimos en un mundo globalizado en el que impera la política liberal, cuyo objetivo es la acumulación de capital, y todo el sistema productivo de bienes y servicios se orienta hacia esa dirección. La producción de alimentos no está fuera de este contexto, por ello también está sujeta a las leyes de oferta y demanda que imponen el libre mercado (Organización de las Naciones Unidas para la Alimentación y la Agricultura [FAO], 2009).

La soberanía alimentaria es una propuesta que se incrusta en la esfera de la política de la producción de alimentos a nivel internacional y que está en franca oposición al modelo liberal. Ambos modelos en la producción de alimentos, modelo de soberanía alimentaria y modelo liberal, son irreconciliables y diametralmente opuestos, manejan los mismos conceptos pero con diferente significado (La Vía Campesina, s. f.).

Por las políticas adoptadas en materia principalmente agraria, los países subdesarrollados o en vías de desarrollo difícilmente van a defender una soberanía alimentaria, porque para sus gobiernos es más barato importar que producir (Pérez, Hernández y Carmona, 2017; Román y Hernández, 2010).

En México, la soberanía alimentaria no es una realidad, importamos aproximadamente $60 \%$ del total de los alimentos que consumimos, lo que nos convierte en un país con dependencia alimentaria, además de la invasión de las cadenas trasnacionales productoras y distribuidoras de alimentos, a las que se les suma la creciente implantación de industrias agroalimentarias.

El concepto de soberanía alimentaria va más allá de la seguridad alimentaria, representa un nuevo ángulo de enfoque del problema mundial de la alimentación. Los elementos constitutivos de esta óptica conceptual de la problemática del hambre y la desnutrición, sin lugar a dudas, representan un nuevo paradigma en esta teorización. Pero más allá de la conceptualización, la soberanía alimentaria representa o significa un reclamo a la humanización de quienes padecen hambre o desnutrición: es la exigencia de más de 800 millones de seres humanos en el mundo para que se les considere como sujetos activos en la solución de esta problemática (FAO, Fondo Internacional de Desarrollo Agrícola [FIDA], Fondo de las Naciones Unidas para la Infancia [Unicef], Programa Mundial de Alimentos [PMA] y Organización Mundial de la Salud [OMS], 2018). Este modelo de análisis de una de las situaciones negativas más agudas y lacerantes de la humanidad elimina de tajo la 


\section{Revista Iberoamericana \\ de las Ciencias Sociales y \\ Humanísticas}

ISSN: $2395-7972$

consideración como objetos a quienes la padecen; la participación activa y definitiva de quienes están inmersos en esta vivencia es necesaria para su solución.

Este nuevo modelo exige, ante todo, un contenido fresco en las definiciones de las políticas públicas en materia de alimentación, de otra manera los hambrientos seguirán siendo solo estadísticas, números cuyo objetivo es disminuir sin importar el cómo (García, 2003).

Analizar con seriedad las implicaciones que conlleva el valor semántico de la soberanía alimentaria es, entre otras cosas, descubrir el enlace entre una situación ponderable y toda una carga axiológica que arrastra la conciencia colectiva, de un pueblo, su cultura y su historia de elementos de identidad. El elemento cultural manifestado en sus costumbres y tradiciones culinarias, así como sus hábitos alimenticios interpretados como un enlace de interacción entre la producción agrícola y las características geofísicas regionales, exigen un respeto irrestricto de quienes son responsables de las políticas públicas agropecuarias, un respeto que debe traducirse en la convicción de que solo es posible la obtención de la seguridad y soberanía alimentaria en la medida en la que los pueblos de las áreas rurales tengan acceso a tierra productiva, a semillas y herramientas apropiadas y a recibir precios justos por sus cosechas que les permitan gozar de una vida digna (Carmona, Paredes y Pérez, 2017).

Priorizar la seguridad alimentaria en un elemento constitutivo de cantidad de tal manera que esto signifique relegar o ignorar los hábitos alimenticios de la población es condenar a esta a sufrir consecuencias no solo socioculturales, sino incluso de orden de salud pública (Carmona et al., 2017).

Los efectos de equivocadas políticas públicas en materia de soberanía alimentaria tarde o temprano laceran a la población y se convierten en un problema más que requiere de programas importantes y urgentes que bien pudieron haberse prevenido. Nuestro país actualmente ostenta un deshonroso primer lugar en obesidad (Instituto de Seguridad y Servicios Sociales de los Trabajadores del Estado [Issste], 3 de abril de 2019). Esta circunstancia es un claro ejemplo de que en materia de alimentación algo no está funcionando bien. Para quienes pregonan que en su entorno no existe el problema de la seguridad alimentaria porque todos tienen alimentos suficientes, habría que indagar acerca de la calidad, procedencia e inocuidad de estos, porque el descuido de factores de este tipo son los que nos han llevado a sufrir un problema de salud cuyas dimensiones no han sido suficientemente concientizadas ni cuantificadas en términos cualitativos (Acuña, 2014). 


\section{Revista Iberoamericana \\ de las Ciencias Sociales y \\ Humanísticas}

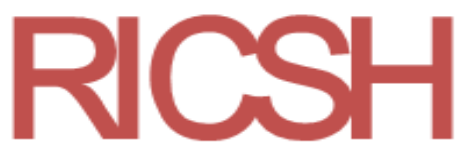

ISSN: $2395-7972$

La soberanía alimentaria es un concepto que se opone decididamente al uso de los alimentos como elemento político manejado principalmente por las grandes potencias contra los países en vías de desarrollo o subdesarrollados. La seguridad alimentaria significa que cada niño, cada mujer y cada hombre deben tener la certeza de contar con el alimento suficiente cada día. Pero el concepto no dice nada con respecto a la procedencia del alimento, o la forma en que se produce (Rosset, 2004).

La soberanía alimentaria puntualiza reiteradamente que la importación masiva de alimentos subsidiados baratos como satisfactor de las necesidades de hambre y desnutrición en un pueblo no es suficiente ni el más deseable; la soberanía alimentaria enfatiza sus propuestas en los mercados y economías locales (Rosset, 2004). La alimentación de un pueblo es un tema de seguridad nacional, de soberanía nacional (Torres y Aguilar, 2006).

Los países que solucionan sus problemas de alimentos abriendo las fronteras a los excedentes de las grandes potencias agroindustriales y privilegiando la libre importación de alimentos y además fomentando, impulsando y apoyando la exportación de la producción alimentaria de calidad, con el único objetivo de fortalecer la macroeconomía y equilibrar la balanza comercial a costa del deterioro de la producción de alimentos para autoconsumo, a la larga se vuelven más dependientes, menos soberanos y están expuestos a los caprichos de sus proveedores alimentarios (La Vía Campesina, s. f.).

Por lo tanto, la principal inquietud manifiesta en este trabajo es indagar acerca de si la soberanía alimentaria en nuestro país es una realidad o pudiera serlo, o simplemente es una ilusión dadas las circunstancias que vivimos y el modelo económico actual que impera a nivel global y, por supuesto, en nuestro territorio. 


\section{Revista Iberoamericana \\ de las Ciencias Sociales y \\ Humanísticas}

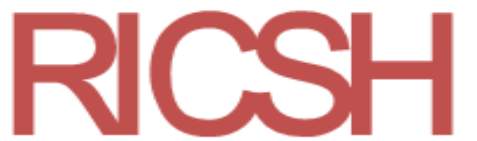

ISSN: $2395-7972$

\section{Metodología}

La metodología empleada en este trabajo es de tipo cualitativo. Incluye una revisión bibliográfica y una histórica del concepto de soberanía alimentaria, su evolución en el mundo hasta aterrizar en el estado actual en México. También se hace una revisión del modelo de producción de alimentos desde la perspectiva de la soberanía alimentaria comparado con el modelo liberal de producción de alimentos.

En el caso del análisis que se hace para nuestro país, se obtuvieron datos de la producción económica de cada sector económico a través de la población económicamente activa (PEA), estos datos abarcan desde el año 1950 hasta el 2019. Dicha información nos brinda un análisis acerca de cómo se ha comportado la producción de alimentos; el comportamiento del sector económico primario dedicado a las actividades agropecuarias funge aquí como balanza.

Se revisan y analizan algunas de las políticas alimentarias, así como programas de Gobierno que han sido implementados a lo largo de la historia de México, con objeto de analizar qué tanto han influido en la posibilidad de llevar a cabo una verdadera soberanía mexicana alimentaria.

\section{Definición de soberanía alimentaria}

Enfrentamos una realidad innegable: el número de personas hambrientas, lejos de disminuir, continúa acrecentándose en un mundo en el que se producen alimentos en abundancia. Es paradójico el hecho de que cada día se producen más alimentos y cada día crece el número de hambrientos y de hambrientas a nivel global (García, 2010). Algo no funciona. Por una parte, los organismos internacionales se reúnen en cumbres, reflexionan, consensuan y determinan políticas encaminadas a erradicar el hambre; muchas organizaciones no gubernamentales $(\mathrm{ONG})$ y agencias de desarrollo intentan implementar estrategias para combatir el hambre y, sin embargo, la incapacidad para alcanzar los objetivos que se proponen se hace presente ineludiblemente. La razón por la que se produce este fenómeno no es difícil de situar: mientras la comida, los alimentos sigan manejándose como un arma política de negociación por parte de los países poseedores de las grandes industrias agropecuarias y mientras no se respete la alimentación como parte integral de los derechos humanos declarados y aprobados por la Organización de las Naciones Unidas [ONU] (1948), 


\section{Revista Iberoamericana \\ de las Ciencias Sociales y \\ Humanísticas}

ISSN: 2395 - 7972

el número de los que padecen hambre seguirá creciendo de acuerdo con los planes de las grandes industrias alimenticias.

La premisa fundamental, mejor dicho, la condición que garantiza un efectivo combate al hambre y a la desnutrición es que las acciones y políticas que se llevan a cabo con este fin deben estar basadas, en primer lugar, en el reconocimiento de que la alimentación es un derecho humano fundamental. La importancia de esta base, de este punto de partida, es que su consideración y respeto pleno genera condiciones y consecuencias que le restarían poder político y económico a las grandes industrias alimenticias trasnacionales porque, entre otras cosas, serían legalmente denunciables aquellas prácticas ejercidas por empresas, gobiernos u organismos de cualquier índole que entorpezcan el ejercicio de este derecho (García, 2003).

La soberanía alimentaria no solo pugna por erradicar el hambre y la desnutrición “como sea"; este modelo va más allá, busca garantizar la perdurabilidad, la eficacia y la sustentabilidad de este combate mediante la producción de alimentos que se fundamente en el desarrollo local y en el respeto a todo lo que implica la localidad.

Se pueden encontrar diferentes definiciones en relación con la soberanía alimentaria, pero el peso de estas siempre estará basado en el concepto de soberanía. Una propuesta es la siguiente:

El derecho de cada pueblo a definir sus propias políticas y estrategias sustentables de producción, distribución y consumo de los alimentos que garanticen una alimentación sana, con base en la micro, pequeña y mediana producción, respetando sus propias culturas y la diversidad de los modos campesinos, pesqueros e indígenas de producción agropecuaria, comercialización y gestión de recursos (Gordillo y Méndez, 2011, p. 34).

Por su parte, Ortega y Rivera (2010) apuntan que la soberanía alimentaria es:

El derecho de los pueblos, comunidades y países a definir sus propias políticas agrícolas, laborales, pesqueras, alimentarias y de tierra de forma que sean ecológica, social, económica y culturalmente apropiadas a sus circunstancias únicas. Esto incluye el verdadero derecho a la alimentación y a la producción de alimentos, lo que significa que todos los pueblos tienen el derecho a una alimentación inocua, nutritiva y culturalmente apropiada, y a los recursos para la producción de alimentos y a la capacidad para mantenerse a sí mismos y a sus sociedades (p. 55). 


\section{Revista Iberoamericana \\ de las Ciencias Sociales y \\ Humanísticas}

ISSN: $2395-7972$

Estas definiciones, como es constatable, no pretenden cumplir con los requisitos que la lógica formal exige para una buena definición, pero en términos de operacionalidad y amplitud descriptiva, indudablemente, cumplen con su objetivo, porque nos proporcionan todos los elementos que de manera inequívoca nos conducen al conocimiento del concepto de soberanía alimentaria.

Desglosar estas definiciones es un ejercicio que ayuda a su comprensión cabal:

- $\quad$ En primer lugar, destaca la ineludible obligación de respetar el derecho a la alimentación y a la producción de alimentos para todos los pueblos y comunidades.

- Los programas encaminados a la producción de alimentos deben respetar los modelos tradicionales de producción agropecuaria y el consumo de alimentos culturalmente acostumbrados.

- Que los gobiernos pongan en marcha políticas y planes que garanticen el acceso a los recursos productivos: tierra, agua, créditos, biodiversidad y tecnología en igualdad de condiciones para hombres y mujeres.

- Acciones que tengan por objetivo la protección social y laboral de los trabajadores y las trabajadoras agrícolas.

- Que la protección a las poblaciones indígenas y rurales se base en el respeto a sus costumbres y tradiciones a sus medios de supervivencia y a su integral forma de vida.

- Priorizar la producción alimentaria orientada a los mercados interiores.

- Rechazar la privatización de los recursos productivos y genéticos.

- Las políticas y programas deben tomar en cuenta la participación activa de los campesinos para su elaboración.

Respecto a los modos de producción de alimentos, la soberanía alimentaria enfatiza que han sido las agriculturas indígenas y las familias campesinas las que han garantizado la alimentación de sus comunidades durante siglos. Y este modelo, que demostró su eficacia y su importante potencialidad de rendimiento hasta antes de la llegada de los modelos liberales, debería recibir decididos apoyos desde las políticas agrarias impulsadas a nivel local e internacional.

Este análisis o discusión no es reciente, ha sido la pugna que por décadas mantienen quienes manejan el alimento como una mercancía más, manipulable su producción según las necesidades, no de la gente, sino de la oferta y la demanda dentro de un mercado globalizado 


\section{Revista Iberoamericana \\ de las Ciencias Sociales y \\ Humanísticas}

ISSN: $2395-7972$

contra los organismos que exigen el respeto del acceso y la producción de alimentos como un derecho y como una forma efectiva de combatir el hambre y la desnutrición.

\section{Soberanía alimentaria vs. modelo liberal de producción de alimentos}

La soberanía alimentaria descansa en la premisa de que las políticas públicas en materia de producción de alimentos asuman su papel de rectoras autónomas y no estén supeditadas a seguir las líneas dictadas por las grandes potencias en materia de industrialización agropecuaria. La realidad que enfrentamos es el contraste entre el modelo basado en las agroexportaciones, las políticas neoliberales y el libre comercio versus el modelo de soberanía alimentaria. El primer modelo ve a los pequeños agricultores como un anacronismo ineficiente que debería desaparecer. El segundo modelo ve a estos pequeños agricultores como la base de las economías locales y del desarrollo económico a nivel nacional (Rosset, 2004).

Es fácil colegir que estos dos modelos sostienen posturas irreconciliables, sus doctrinas predican principios y fundamentos totalmente opuestos. La avalancha globalizadora que engulle las economías de los países que están en vías de desarrollo y los propios países subdesarrollados no han permitido una apropiada defensa de sus sistemas históricos de producción de alimentos y se han visto devorados por los monopolios industrializadores de alimentos que los han orillado a la producción focalizada de alimentos con fines de exportación al mismo tiempo que los inundan de sus excedentes de poca calidad.

Estas grandes industrias alimentarias han aprovechado con eficacia las grandes crisis económicas que afectan con mayor severidad a los países menos protegidos y les han impuesto políticas de comportamiento económico y agropecuario utilizando a los alimentos como una de sus armas más eficaces. Esta forma de hacer política ha fracturado de raíz la diversidad en la producción de alimentos para autoconsumo, que ha sido uno de los pilares fundamentales de las agriculturas campesinas porque les ha permitido, además de alimentarse adecuadamente, fomentar el comercio local-regional de temporada, formar agroecosistemas ricos, sustentables y diversos, fortalecer una economía local y regional que les ha permitido ser autónomos y soberanos en su alimentación y en su desarrollo.

Este tesoro, que han cuidado y respetado los pueblos campesinos durante miles de años para procurar alimentos, debería defenderse porque representa la esencia de la soberanía alimentaria; sin embargo, hoy se encuentra en agonía (García, 2003). 


\section{Revista Iberoamericana \\ de las Ciencias Sociales y \\ Humanísticas}

ISSN: $2395-7972$

Los modelos en pugna, soberanía alimentaria vs. liberalismo, manejan los mismos conceptos pero con significado diferente y, en algunos casos, totalmente opuesto. En un ejercicio de análisis de significado, se rescatan algunos conceptos propuestos por estudiosos y especialistas en el tema, tal y como Rosset (2004).

Tabla 1. Modelo de soberanía alimentaria vs. modelo liberalismo

\begin{tabular}{|c|c|c|}
\hline Concepto & Modelo soberanía alimentaria & Modelo liberalismo \\
\hline Alimentos & $\begin{array}{l}\text { Un derecho humano; deben ser: saludables, } \\
\text { nutritivos, asequibles culturalmente apropiados y } \\
\text { producidos localmente. }\end{array}$ & $\begin{array}{l}\text { Una mercancía. El } \\
\text { único objetivo es que } \\
\text { produzcan mayores } \\
\text { ganancias. }\end{array}$ \\
\hline Hambre & $\begin{array}{l}\text { Un problema de acceso y distribución debido a la } \\
\text { pobreza y a la desigualdad. }\end{array}$ & $\begin{array}{l}\text { La padecen quienes no } \\
\text { son productivos. }\end{array}$ \\
\hline Producir & Un derecho de los pueblos rurales & $\begin{array}{l}\text { Una opción para los } \\
\text { más eficientes }\end{array}$ \\
\hline Campesinos & $\begin{array}{l}\text { Productores de alimentos para autoconsumo. } \\
\text { Guardianes de la biodiversidad de los cultivos. } \\
\text { Base del mercado interno para el desarrollo local. } \\
\text { Productivo. Administrador de los recursos } \\
\text { naturales. }\end{array}$ & $\begin{array}{l}\text { Anacronismo, deben } \\
\text { desaparecer por } \\
\text { ineficientes. }\end{array}$ \\
\hline $\begin{array}{l}\text { Recursos } \\
\text { naturales }\end{array}$ & Controlados y administrados por la comunidad. & Deben privatizarse. \\
\hline Semillas & $\begin{array}{l}\text { Una herencia de los pueblos al servicio de la } \\
\text { comunidad. }\end{array}$ & $\begin{array}{l}\text { Una mercancía } \\
\text { patentable. }\end{array}$ \\
\hline Subsidios & $\begin{array}{l}\text { Deben otorgarse a los agricultores familiares para } \\
\text { la comercialización directa, el apoyo de los } \\
\text { precios o ingresos, la conservación del suelo, la } \\
\text { práctica de una agricultura sostenible, la } \\
\text { investigación, etc. }\end{array}$ & $\begin{array}{l}\text { Deben darse a los } \\
\text { agroindustriales a gran } \\
\text { escala con fines de } \\
\text { explotación y práctica } \\
\text { del dumping. }\end{array}$ \\
\hline Dumping & Debe prohibirse y castigarse. & No es un problema. \\
\hline
\end{tabular}




\section{Revista Iberoamericana \\ de las Ciencias Sociales y \\ Humanísticas}

ISSN: 2395 - 7972

\begin{tabular}{|c|c|c|}
\hline Monopolio & Debe prohibirse y castigarse. & $\begin{array}{c}\text { No es problema, es } \\
\text { parte del libre mercado. }\end{array}$ \\
\hline Comercio & $\begin{array}{c}\text { Alimentos, agricultura y recursos naturales deben } \\
\text { quedar fuera de los acuerdos comerciales }\end{array}$ & $\begin{array}{l}\text { Todo queda supeditado } \\
\text { al libre mercado. }\end{array}$ \\
\hline $\begin{array}{l}\text { Prioridad } \\
\text { productiva }\end{array}$ & Alimento para mercados locales como prioridad. & $\begin{array}{c}\text { Agroexportaciones a } \\
\text { gran escala. }\end{array}$ \\
\hline $\begin{array}{l}\text { Precios de } \\
\text { los cultivos }\end{array}$ & $\begin{array}{c}\text { Precios justos que cubran con los gastos de } \\
\text { producción y permitan a los agricultores una sana } \\
\text { vida. }\end{array}$ & $\begin{array}{l}\text { Los que el libre } \\
\text { mercado dicte. }\end{array}$ \\
\hline $\begin{array}{l}\text { Crédito e } \\
\text { inversiones } \\
\text { rurales }\end{array}$ & $\begin{array}{l}\text { Del sector público, dirigido a la agricultura } \\
\text { familiar, principalmente para autoconsumo y } \\
\text { abastecimiento de los mercados locales. }\end{array}$ & $\begin{array}{l}\text { Del sector privado con } \\
\text { fines de privatización. }\end{array}$ \\
\hline $\begin{array}{l}\text { Seguridad } \\
\text { alimentaria }\end{array}$ & $\begin{array}{l}\text { Es posible cuando la producción de alimentos está } \\
\text { en manos de los propios campesinos, y cuando los } \\
\text { alimentos se producen localmente. }\end{array}$ & $\begin{array}{l}\text { Se logra importando } \\
\text { alimentos desde donde } \\
\text { son más baratos. }\end{array}$ \\
\hline
\end{tabular}

Fuente: Elaboración propia con base en Rosset (2004)

La discrepancia o antagonismo que existe entre estos dos modelos, en cuanto a soberanía alimentaria se refiere, es patente y no deja lugar a dudas. No se trata únicamente de significado, de teorización o de conceptos, se trata de prácticas desleales de las grandes potencias agroindustriales y de las leyes y reglamentos que rigen a los organismos internacionales que no son favorables para sus afiliados más vulnerables, a quienes obligan a producir exclusivamente para la exportación (Altieri, 1999). 


\section{Revista Iberoamericana \\ de las Ciencias Sociales y \\ Humanísticas}

ISSN: $2395-7972$

\section{La soberanía alimentaria en las tribunas públicas internacionales}

\section{Foro Mundial sobre Soberanía Alimentaria. La Habana, Cuba, 2001. "Por el derecho de los pueblos a producir, alimentarse y a ejercer su soberanía alimentaria"}

Del 3 al 7 de septiembre del 2001 se llevó a cabo el Foro Mundial sobre Soberanía Alimentaria en la Habana, Cuba. En su declaración final ${ }^{1}$ están contenidas las brechas profundas que separan la conceptualización de la soberanía alimentaria de la conceptualización del modelo económico neoliberal vigente en el mundo.

Un elemento que es innegable reconocer como aportación de esta declaración, fruto de las reflexiones y el análisis de la temática de este foro, es el lenguaje más fresco, menos tecnificado, más accesible, así como la carga emocional que acompaña a los contenidos de sus conclusiones.

La declaración final del foro hace hincapié en que el derecho a alimentarse y al bienestar nutricional, a pesar de estar contenido en la Declaración Universal de los Derechos Humanos, es letra muerta en la mayoría de los países del mundo. Enfatiza que el objetivo del foro es el análisis y la construcción colectiva del problema y sus soluciones desde la perspectiva de los pueblos y no de las corporaciones alimentarias trasnacionales.

Las causas reales del hambre y malnutrición son:

Las políticas económicas, agrícolas y comerciales a escala mundial, regional y nacional que han sido impuestas por los poderes de los países desarrollados y sus corporaciones, en su afán de mantener y acrecentar su hegemonía política, económica, cultural y militar en el actual proceso de restructuración económica global (Foro Mundial sobre Soberanía Alimentaria, 2001).

Entre sus planteamientos ideológicos contenidos en su declaración final, deben mencionarse entre los más importantes:

- Los alimentos no son una mercancía más y el sistema alimentario no puede ser tratado con la lógica del libre mercado.

- Los países subdesarrollados son capaces de producir sus propios alimentos.

- La importación de alimentos básicos "más baratos" desmantela la producción doméstica.

\footnotetext{
${ }^{1}$ Publicada en Regiones y Desarrollo Sustentable, publicación semestral de El Colegio de Tlaxcala, A. C., año III, enero-junio, 2003.
} 


\section{Revista Iberoamericana \\ de las Ciencias Sociales y \\ Humanísticas}

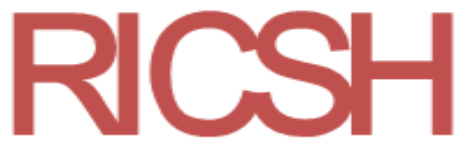

ISSN: $2395-7972$

- Es mentira que la importación de alimentos resuelve cualquier problema de seguridad alimentaria.

- $\quad$ Es mentira que las agriculturas campesinas e indígenas son ineficientes e incapaces de responder a las necesidades crecientes de la producción de alimentos.

- $\quad$ Se rechaza que la forma de hacer frente a las necesidades crecientes de alimentos en el mundo sea a través de la agricultura y la pesca a gran escala, industrial e intensiva.

Estas declaraciones finales vierten conceptos que, a fuerza de ser repetitivos, parecen ya no impresionar, pero es una realidad cuyos efectos perniciosos deberían ser mejor concientizados. No podemos negar la existencia de una concentración del mercado agrícola internacional en unas cuantas empresas trasnacionales que son protegidas por sus países, al mismo tiempo que aumenta la dependencia alimentaria de los pueblos, principalmente de América Latina y el Caribe (Foro Mundial sobre Soberanía Alimentaria, 2001).

Actualmente, aun en los países cuyo discurso oficial es considerar al campo como prioridad, se está subsidiando fuertemente a la agricultura y pesca de exportación en tanto que se deja totalmente desprotegidos a los pequeños productores que abastecen principalmente los mercados locales.

\section{Foro Social Mundial. Porto Alegre, Brasil, 2002. "Otro mundo es posible. Declaración mexicana de los movimientos sociales"}

Este foro fue celebrado del 31 de enero al 5 de febrero del 2002 y su objetivo primordial fue discutir, analizar y construir propuestas emanadas de los pueblos y organizaciones sociales y civiles ante un modelo neoliberal que provoca la destrucción de nuestras culturas, economías y medio ambiente.

En lo que respecta a nuestro tema de soberanía alimentaria, la aportación de la delegación mexicana fue la siguiente:

México, centro de origen de semillas y granos básicos como el maíz y el frijol, que constituyen parte de nuestra identidad y de nuestra vida, ha sido invadido ya por transgénicos y le ha sido robado patentes y saberes que eran patrimonio de las comunidades y de la humanidad. Exigimos la protección de las semillas originarias y de la biodiversidad y que se impida la entrada al país de organismos genéticamente modificados (II Foro Social Mundial, 2003). 


\section{Revista Iberoamericana \\ de las Ciencias Sociales y \\ Humanísticas}

ISSN: $2395-7972$

En otros apartados, la propia delegación mexicana se suma decididamente a la lucha por el derecho a la tierra y por el derecho a la alimentación suficiente y equilibrada.

Los objetivos de este tipo de foros que no tienen carácter oficial porque no están avalados o convocados por organismos reconocidos internacionalmente como la FAO, el Unicef, la Organización para la Cooperación y el Desarrollo Económicos (OCDE), por mencionar algunos, son eminentemente de difusión y cumplen sobradamente con su propósito, pues de otra manera los temas que se discuten no serían conocidos o no tendrían la oportunidad de levantar inquietudes. En cuanto al contenido de las declaraciones vertidas por la delegación mexicana, no está fuera de la realidad; lo importante sería canalizar adecuadamente las exigencias de tal manera que tuvieran un margen, aunque sea mínimo, de atención.

\section{Foro Social Mundial. Porto Alegre, Brasil, 2003. "Posición sobre soberanía alimentaria de los pueblos. Nuestro mundo no está en venta, primero está la soberanía alimentaria de los pueblos"}

El contenido de este foro reiteró y reforzó las ideas que se tienen acerca de la amenaza que representan las políticas neoliberales que socavan a la agricultura familiar y, por lo tanto, a la alimentación y soberanía alimentaria.

Los términos que maneja al definir la soberanía alimentaria tienen una carga de significado que reitera atinadamente la conceptualización generalizada de esta.

Sus conclusiones reclaman que los gobiernos deben apoyar y aplicar políticas que fomenten una producción sustentable, basada en la producción familiar campesina, en lugar de un modelo industrial de altos insumos y orientado a la exportación.

Estas políticas deben tener características y orientaciones que persigan ante todo una soberanía alimentaria como fruto de un desarrollo local y regional.

- Deben ejercer el derecho de proteger a los mercados nacionales ante productos importados a bajo precio.

- Brindar apoyo a prácticas agropecuarias y pesqueras sustentables y a programas de reforma agraria integral.

- $\quad$ Proteger el medio ambiente a fin de garantizar la seguridad e inocuidad de los alimentos. 


\section{Revista Iberoamericana \\ de las Ciencias Sociales y \\ Humanísticas}

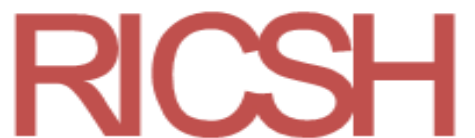

ISSN: $2395-7972$

- $\quad$ Promover y proteger el acceso a los recursos productivos, a los pequeños productores.

- Sentar bases apropiadas para desarrollar economías locales.

- $\quad$ Prohibir la producción y comercialización de semillas, alimentos y piensos genéticamente modificados.

- Denunciar e impedir el uso de alimentos transgénicos como ayuda alimentaria.

- $\quad$ Fijar normas agrícolas que permitan conocer el origen y contenidos de los alimentos destinados al consumo humano y animal.

- $\quad$ Promulgar leyes severas contra la práctica del dumping (III Foro Social Mundial, 2003).

Es innegable la existencia de redes, movimientos y ONG que pugnan por una toma de conciencia universal acerca de las nefastas consecuencias que tienen las políticas neoliberales sobre el desarrollo sustentable de las comunidades rurales, principalmente, sobre sus sistemas históricos de producción, sobre su acceso a los recursos naturales, en fin, sobre una seguridad y soberanía alimentaria elemental. El enemigo que enfrentan es muy difícil de vencer porque, como modelo predominante actual, es el dueño del poder y del dinero.

El panorama mundial muestra una red de intereses que dificulta la consecución de la soberanía alimentaria, sobre todo de los países en vías de desarrollo. Estas dificultades parecen imposibles de vencer especialmente porque los contendientes son muy asimétricos: por un lado, están las familias rurales campesinas que producen para el autoconsumo y abastecimiento local, y por el otro, están las agroindustrias y las importaciones masivas de excedentes alimentarios baratos de otros países. El resultado es predecible: el deterioro en la capacidad de producción de alimentos para autoconsumo y abastecimiento local, lo que significa pérdida de soberanía alimentaria.

\section{La soberanía alimentaria en México}

México es un país privilegiado en cuanto a su potencial de productor en el sector primario, por ello en la década de los 70 se decía que el nuestro no era un país subdesarrollado sino subadministrado (Melgoza, 1972), y son precisamente las políticas en materia agropecuaria de los diferentes gobiernos las que han llevado a la nación mexicana a una situación de dependencia alimentaria. Hasta la última década del siglo pasado, los campesinos mexicanos tanto ejidatarios como pequeños propietarios representaban una PEA 


\section{Revista Iberoamericana de las Ciencias Sociales y Humanísticas}

en el sector primario económico mayoritaria, solo faltaban políticas gubernamentales decisivas que impulsaran la producción agropecuaria y que garantizaran el abasto interno mediante los mercados locales y regionales, de tal manera que se garantizara no solo la producción de alimentos para autoconsumo, sino, incluso, un ataque objetivo y frontal contra el hambre, la desnutrición y la pobreza; lejos de esto, se firma el Tratado de Libre Comercio de América del Norte (TLCAN), que encadena a nuestro país a los poderosos del norte en materia alimentaria. La firma de este tratado parece marcar el inicio de una imparable marcha hacia la pérdida de la soberanía alimentaria en México.

Si nos remitimos a datos históricos, podemos observar cómo paulatinamente el sector correspondiente a las actividades agrícolas, es decir, el sector primario, ha venido disminuyendo. En la tabla 2 podemos comprobar cómo las actividades económicas con respecto al sector económico de actividad han cambiado radicalmente y se ha dado una inversión entre el sector primario y el terciario. De hecho, este sector es el que más ha crecido y el sector primario el único que ha disminuido drásticamente, lo que ha generado la disminución de la producción de alimentos y la necesidad de importar todo aquello que no se está produciendo.

Tabla 2. Población ocupada por sector de actividad 1950-1990

\begin{tabular}{|l|c|c|c|c|c|c|c|c|c|c|}
\hline \multicolumn{1}{|c|}{ Año } & \multicolumn{2}{c|}{1950} & \multicolumn{2}{c|}{1960} & \multicolumn{2}{c|}{1970} & \multicolumn{2}{c|}{1980} & \multicolumn{2}{c|}{1990} \\
\hline Total & 8272093 & 11332016 & 12955057 & 21393250 & \multicolumn{2}{c|}{23403413} \\
\hline Sector & $\#$ & $\%$ & $\#$ & $\%$ & $\#$ & $\%$ & $\#$ & $\%$ & $\#$ & $\%$ \\
\hline Primario & 4823901 & 58.32 & 6143540 & 54.21 & 5103519 & 39.39 & 5519979 & 25.80 & 5300114 & 22.65 \\
\hline Secundario & 1319163 & 15.95 & 2147343 & 18.95 & 2973540 & 22.95 & 4424826 & 20.68 & 6503224 & 27.79 \\
\hline Terciario & 1774063 & 21.45 & 2959342 & 26.11 & 4130473 & 31.88 & 5197712 & 24.30 & 10796203 & 46.13 \\
\hline No & & & & & & & & & & \\
especificado & 354966 & 4.29 & 81791 & 0.72 & 747525 & 5.77 & 6250733 & 29.22 & 803872 & 3.43 \\
\hline
\end{tabular}

Fuente: Elaboración propia con base en el Instituto Nacional de Estadística y Geografía

[Inegi] (1999)

Esta disminución en cuanto a la producción de actividades agropecuarias ha continuado de manera ininterrumpida, mientras que el sector correspondiente a comercio y servicios ha seguido aumentando, como ha sucedido en las últimas décadas, así lo constatan los datos de los organismos oficiales. 


\section{Revista Iberoamericana \\ de las Ciencias Sociales y \\ Humanísticas}

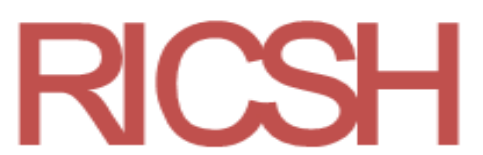

ISSN: 2395 - 7972

En México, el abandono de la rectoría del estado del sector primario de las actividades económicas, principalmente de la agricultura, fue la firma que permitió el ingreso de este sector al libre mercado y, por lo tanto, la agudización del proceso de extinción de los pequeños campesinos y, aún más, la aceleración de la pérdida de soberanía alimentaria debido a la invasión de las cadenas trasnacionales agroindustriales y alimentarias. Este apoderamiento que el capital ejerce sobre el sector primario en nuestro país inicia de manera incontenible en el sexenio salinista y hasta el inmediato anterior su crecimiento y agudización no se han detenido.

\section{Resultados y discusión}

La disminución de la producción e importación masiva de alimentos de consumo básico en México es un problema grave que debe estar entre las prioridades de seguridad nacional. Cereales como maíz, trigo y arroz o la leche de vaca, que son elementales en la dieta diaria de los mexicanos, se compran en cantidades significativas para abastecer la demanda. Por ejemplo, en el año 2016, México importó 14.2 millones de toneladas de maíz (34.9\% del consumo aparente nacional) y 2541 millones de litros de leche (18\% del consumo aparente nacional), cantidades que a lo largo del tiempo no se han reducido, y más bien se han mantenido cuando menos en la última década (Servicio de Información Agroalimentaria y Pesquera [SIAP], 2017).

El déficit de estos alimentos básicos de consumo humano (entre otros) se debe a diversos factores, tales como la firma del TLCAN, lo cual ha implicado que miles de campesinos hayan abandonado las tierras agrícolas debido a que los productos importados son mucho más baratos (aunque de dudosa calidad), hayan emigrado y buscado otras alternativas o, incluso más recientemente, hayan salido de sus lugares de origen a raíz de la inseguridad y el crimen organizado que se vive en varias zonas de la república mexicana.

También los hogares campesinos han reducido su producción de maíz, frijol, trigo, leche y otros alimentos más debido a los altos costos de producción y los bajos precios, lo cual ha implicado una disminución en su productividad. Ahora ha aumentado la compra de alimentos porque es más barato que producirlos o porque el conocimiento de cómo producirlos se ha perdido paulatinamente (Pérez et al., 2017; Pérez y Hernández, 2019; Román y Hernández, 2010;). 


\section{Revista Iberoamericana \\ de las Ciencias Sociales y \\ Humanísticas}

ISSN: $2395-7972$

Durante el sexenio 2000-2006, el país dejó de ser autosuficiente en la producción de sus granos básicos; pese a que mantenía la autosuficiencia del maíz, las importaciones de cereal se incrementaron en 157 \%, lo revela el Informe General Ejecutivo. Cuenta Pública 2016 elaborado por la Auditoría Superior de la Federación [ASF] (2008, citado en Ramírez, 2008). Durante el mismo sexenio, la evaluación de desempeño aplicada al Programa de Fomento Agrícola (instrumento a cargo de la Secretaría de Agricultura y Desarrollo Rural [Sagarpa]) muestra que la balanza de productos agrícolas para el periodo 2000-2005 se vuelve deficitaria principalmente por las crecientes importaciones de cereales y oleaginosas. Datos del mismo periodo muestran, según cálculos de la ASF, que la dependencia alimentaria se siguió incrementando, pues, según cifras del SIAP en 2002, se importaba $41.2 \%$ de los alimentos que se consumían en el país, mientras que para el 2006 ya se importaba $42.5 \%$ (Ramírez, 2008).

En el sexenio del presidente Felipe Calderón (2006-2012), la situación en materia de soberanía alimentaria no mejoró: al anunciar la libre importación de maíz, arroz, trigo, sorgo y soya proveniente de cualquier parte del mundo y apoyar de manera desmedida a los grandes productores agropecuarios con fines de exportación como lo hizo el Gobierno federal, (Rubio, 2008), en ese momento se renuncia a velar por la soberanía alimentaria.

Estos anuncios despertaron reacciones inmediatas como los de la Asociación Nacional de Empresas Comercializadoras del Campo (ANEC), que lamentó que el Gobierno "no reconozca que ya hay una crisis alimentaria en México; que, además la promueve activamente con la iniciativa para traer alimentos de cualquier parte del mundo sin arancel" (Ramírez, 2008, párr. 6). El presidente refuerza el modelo de depositar en el exterior la seguridad alimentaria de los mexicanos. A principios del sexenio del presidente Vicente Fox (2000-2006), el Gobierno importaba $42.5 \%$ de los alimentos y se calculaba que al finalizar su mandato la dependencia alimentaria se incrementaría 60 \% (Ramírez, 2008). Estas cifras revelan un retroceso significativo en lo que a soberanía alimentaria se refiere, sobre todo si se considera que un país es dependiente alimentario si sus importaciones de alimentos son de $45 \%$ o más (Ramírez, 2008).

La situación de la soberanía alimentaria en México podría resumirse de la siguiente manera: la existencia de dos tipos de productores agropecuarios: por un lado, un sector altamente capitalizado, moderno, monopólico, empleador de fuerza de trabajo, etc., y en contraste, otro sector caracterizado por escasa o nula capitalización, atrasado 


\section{Revista Iberoamericana \\ de las Ciencias Sociales y \\ Humanísticas}

ISSN: 2395 - 7972

tecnológicamente con producción de subsistencia, lanzado paulatinamente al trabajo asalariado, a la emigración o a la mendicidad (Salinas, 1990).

Argelia Salinas Ontiveros, maestra en Economía Agrícola por el Instituto de Investigaciones Económicas de la Universidad Nacional Autónoma de México (UNAM), en una entrevista que concedió a Radio UNAM en el marco de la temática "El campo mexicano en los planes de la administración del Gobierno del presidente Felipe Calderón Hinojosa", llevada a cabo el 13 de febrero de 2014, se muestra francamente pesimista en cuanto al futuro del campo; reconoce que es temprano para dar una calificación categórica, pero si no cambian las cosas estamos mandando a los pequeños campesinos a engrosar las filas de los cinturones de pobreza de las grandes ciudades.

Las apreciaciones de la maestra Salinas son realistas. Los datos duros nos muestran en diferentes estudios informaciones similares: la PEA está cambiando de actividad económica de manera espectacular: el sector primario que representaba el mayor porcentaje de ocupación en las poblaciones rurales estudiadas ha venido disminuyendo desde la década de los 70 a tal grado que ya en el año 2000 la PEA del sector primario en estas localidades ocupaba el segundo lugar, y mientras que las tendencias del sector secundario y terciario ya eran de crecimiento, el sector primario mostraba una caída significativa (Carmona, 2008, 2013).

Figura 1. PEA por sectores económicos correspondiente al cuarto trimestre de 2017

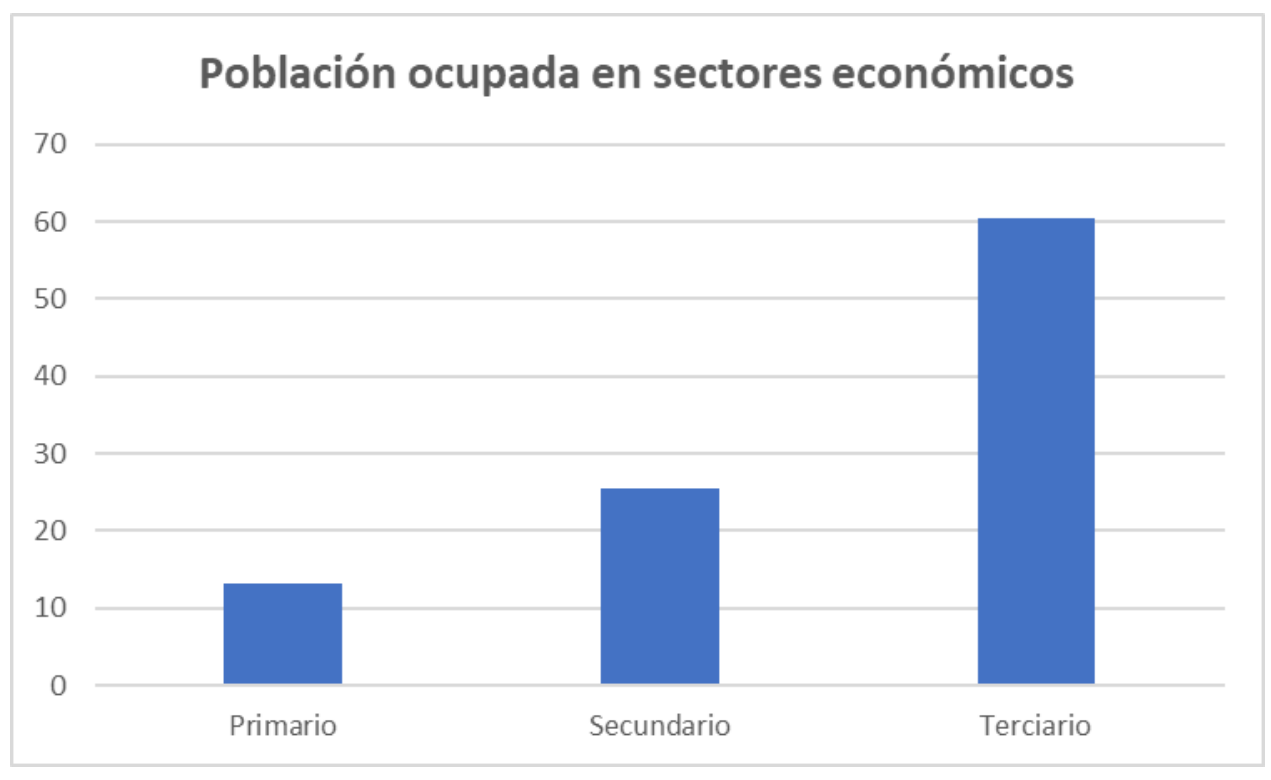

Fuente: Elaboración propia con base en Inegi (2018) 


\section{Revista Iberoamericana \\ de las Ciencias Sociales y \\ Humanísticas}

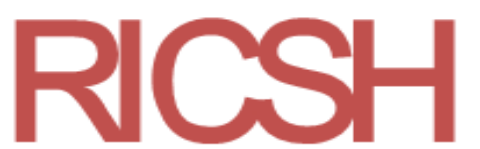

ISSN: 2395 - 7972

En la figura 1 se observa definitivamente esta marcada tendencia. La ocupación de la PEA en nuestro país, según las cifras proporcionadas por el Inegi para el cuarto trimestre del año 2017, muestra un contraste muy claro: por un lado, destaca $60.5 \%$ de la población total, la cual se dedica ahora al sector terciario, mientras que el sector primario solo representa $13.3 \%$ y al sector secundario corresponde a $25.6 \%$ ( $0.6 \%$ de la población no especificó su actividad económica). Indudablemente estos porcentajes dejan en claro el abandono perdurable de las actividades del sector primario.

Para el año 2019, la población dedicada al sector primario sigue disminuyendo: corresponde a $12.6 \%$; mientras que el sector que sigue incrementándose es el representado por las actividades de comercio y servicios, es decir, el terciario, el cual tiene $61.6 \%$, mientras que el secundario presenta $25.16 \%$ y un $0.64 \%$ que no especificó su actividad (Secretaría del Trabajo y Previsión Social [STPS], 2020). El abandono de las actividades agropecuarias conlleva a la pérdida de soberanía alimentaria, se ha dejado de producir alimentos y, por consiguiente, la dependencia alimentaria hacia los países proveedores es cada vez mayor.

Otra variable digna de considerar, que de alguna manera influye en el pesimismo de un posible rescate de la soberanía alimentaria en México, es que mientras los programas gubernamentales no superen las deficiencias en su operacionalidad mediante seguimientos y evaluaciones continuas no se van a conseguir los objetivos para los que se crean. Ya es una costumbre que los programas gubernamentales para el desarrollo agrícola son casi perfectos en su lógica de planeación, pero fallan en su lógica de gestión, lo que los vuelve inoperantes (Centro de Estudios para el Desarrollo Rural Sustentable y la Soberanía Alimentaria [CEDRSSA], 2007).

En un artículo de Erika Ramírez que data de 2005 pero cuyo contenido sigue vigente, la autora afirma que 13 grandes transnacionales productoras de alimentos, entre las que se encuentran Walmart, Bayer, Dupont, Nestlé, Carrefour, entre otros, están deteriorando la productividad del campo mexicano a nivel de pequeños campesinos. Estos agronegocios en el ámbito internacional han tenido a México como uno de sus objetivos para posicionarse en su mercado, así lo señalan expertos en la materia, lo que traerá como consecuencias, según Ramírez (2005), la pérdida de soberanía alimentaria y más miseria en el campo, miseria que, en ese entonces, sumaba entre sus filas a más de 25 millones de mexicanos. 


\section{Revista Iberoamericana \\ de las Ciencias Sociales y \\ Humanísticas}

ISSN: $2395-7972$

La investigadora Ramírez (2005) cita al entonces presidente del CEDRSSA, quien comenta que el sector agroalimentario mexicano ha sido entregado a las grandes transnacionales extranjeras, las cuales están estableciendo patrones de consumo a toda la nación. El contenido de esta declaración es sumamente grave, indica que no solo dependemos alimentariamente del extranjero, sino que incluso se nos imponen patrones alimentarios a capricho y conveniencia de las transnacionales.

El ataque frontal a las causas del hambre y la pobreza exige una combinación real de las capacidades productivas de la agricultura campesina, con una gestión sustentable de los recursos productivos y con políticas gubernamentales que garanticen la alimentación adecuada de la ciudadanía con independencia de las leyes que rigen el comercio internacional. Este objetivo o propuesta parece platónico en un mundo tan infectado por el liberalismo económico.

Los países poderosos poseedores de una industria alimentaria creada ex profeso para la exportación jamás permitirán que los países del tercer mundo o en vías de desarrollo dejen de ser sus clientes cautivos, utilizarán estrategias permitidas y no permitidas, pero siempre tendrán a estos países como destino asegurado de la población de su industria alimentaria.

Los países pobres difícilmente arriesgarán perder la "protección" que les brindan los países proveedores de alimentos, y solo les resta respetar la "línea" de comportamiento económico que les dictan los países más desarrollados. Estos países definitivamente "no pueden”, en la práctica, establecer políticas alimentarias soberanas.

La soberanía alimentaria en países subdesarrollados y en vías de desarrollo es definitivamente una quimera. La administración de la pobreza que practican los dueños del poder político y económico tienen como uno de sus objetivos mantener en estos países un estatus apropiado para sus intereses de expansión y enriquecimiento.

Las grandes agroindustrias y cadenas trasnacionales alimentarias ya no soltarán a su presa, su expectativa es que la propia dinámica de la movilidad capitalista y la inefectividad de la producción agrícola interna a causa de políticas agropecuarias equivocadas las lleve a convertirse en un satisfactor en lugar de un invasor en los países donde se han asentado.

La soberanía alimentaria es una quimera en estos países porque es fantasioso pensar que exista un presidente que, contra toda lógica, apueste su capital político asumiendo la rectoría de la producción alimentaria, impulsando la producción agropecuaria a nivel local, regional y nacional con los apoyos necesarios, desde el acceso a la tierra y recursos naturales, 


\section{Revista Iberoamericana \\ de las Ciencias Sociales y \\ Humanísticas}

ISSN: 2395 - 7972

insumos para los cultivos hasta los mercados apropiados. A cualquier presidente le "sale más barato" importar que producir.

Pudiera pasar de quimera a ser una posibilidad aquí en México si se establecen programas de rescate de la actividad agrícola a nivel de pequeños campesinos, es decir, poner en marcha programas cuyo objetivo sea hacer atractivo al campo. De todos es sabido que, a nivel de pequeños campesinos, los actuales son mayores de 45 años y los hijos de estos no tienen la intención de continuar con esta actividad porque no es redituable, no tienen ningún estímulo que los animen a continuar con la actividad del padre; los mismos campesinos actualmente han tenido que buscar otras alternativas de obtención de ingreso: ahora son todo menos campesinos (Carmona, 2008, 2013). La posibilidad de que la soberanía alimentaria se rescate, al menos parcialmente, mediante esta práctica es lejana y además no a corto plazo, pero al fin y al cabo es posibilidad.

En suma, la soberanía alimentaria, al menos en nuestro país, no es una realidad, y no lo es debido a que estamos invadidos de trasnacionales en el terreno de la agricultura y en el terreno de las cadenas productoras y distribuidoras de alimentos y además porque la libre importación de granos y otros productos de cultivo crece más cada día.

La reflexiones de Altieri (1999) son sensatas y reales cuando advierte que los países de América Latina y el Caribe en el pasado han sido soberanos en su alimentación, sin embargo, hoy son pocos y en menor medida los que lo siguen siendo. La causa es la creciente globalización, que trae consigo la aplicación de políticas liberales y la asociación a organismos internacionales que aplican sus reglamentos y obligaciones que favorecen a los países más poderosos, de esta manera los países menos desarrollados caen en la paradoja de producir para exportar e importar para el consumo interno.

En los países industrializados es posible que la soberanía alimentaria sea una realidad, sin embargo, incluso en estos algún elemento constitutivo de la definición de soberanía alimentaria está ausente, ya sea la sustentabilidad, el acceso a la producción sin discriminación de género, el respeto a las preferencias alimenticias, la libre elección de cultivos, el uso de semillas genéticamente modificadas, recursos naturales privatizados o administrados por los estados, etc. El argumento más fuerte para afirmar que incluso en los países más industrializados no existe una verdadera soberanía alimentaria es que son practicantes y mantenedores del libre comercio en el que el capital es el único motor de 


\section{Revista Iberoamericana \\ de las Ciencias Sociales y \\ Humanísticas}

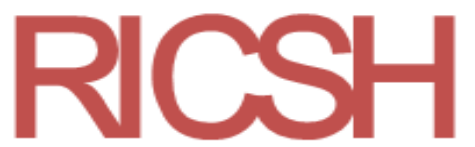

ISSN: $2395-7972$

desarrollo. En nuestro mundo globalizado difícilmente se va a encontrar un país con una soberanía alimentaria tal y como se define de manera conceptual y operacional.

\section{Conclusiones}

El presente trabajo cumple con los objetivos que se plantearon al inicio. Se realizó una revisión exhaustiva del concepto de seguridad alimentaria, se analizaron los diferentes foros en los que se ha discutido este concepto y las conclusiones de cada uno de ellos. Además, se menciona y discute el modelo liberal de producción de alimentos contra el modelo de soberanía alimentaria. Posteriormente se revisa el estado de la soberanía alimentaria en México. Y se concluye que, por el momento, en nuestro país no es posible alcanzar una soberanía alimentaria. Las causas son demasiadas y muy variadas. Por un lado, la disminución de la población ocupada en el sector primario disminuyó drásticamente, es decir, el abandono de las actividades agropecuarias es casi total. Como se mencionó, en el año 2019 solo $12.6 \%$ del total se dedica a este sector, según cifras oficiales. La reforma en 1994 al artículo 27 constitucional coadyuvó al abandono de esta actividad, pues permitió la venta de ejidos que garantizaban de alguna manera la producción de alimentos para autoconsumo y comercio del excedente en mercados locales o regionales. Después de esta reforma, los campesinos no solo no producen alimentos, sino que ahora también los demandan. Una vez deteriorada esta capacidad de producción de alimentos, y ante el aumento de la demanda de estos productos a raíz de su mermada producción, el Gobierno optó no por resarcir esta falta de producción de alimentos y reactivar el campo con políticas favorables, sino que se decidió a importar todos esos faltantes, porque además es más barato comprarlos que poner en marchas programas para producirlos.

Tenemos que reconocer que la soberanía alimentaria en México es una quimera con un porcentaje muy bajo de posibilidades. No obstante, si bien no es realista revertir del todo esta situación actualmente, sí que lo es aminorarla y lograr una soberanía alimentaria al menos parcial. Para lograr esto, es indispensable la creación de programas agresivos que hagan redituable al campo, establecer precios justos y que motiven a las nuevas generaciones a la práctica de actividades agrarias, porque, como se ha visto en estudios anteriores, a las nuevas generaciones no les interesa el campo, saben que no es redituable, que no se puede vivir de él, y los campesinos actuales, lamentablemente, debido a las políticas actuales, son 


\section{Revista Iberoamericana \\ de las Ciencias Sociales y \\ Humanísticas}

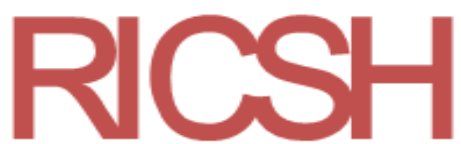

ISSN: 2395 - 7972

orillados a buscar otras alternativas de obtención de ingresos para sobrevivir, lo que los obliga a abandonar el campo y muchas veces su propio lugar de origen.

Las principales fortalezas de este trabajo, además de la revisión meticulosa y pormenorizada de la teoría sobre soberanía alimentaria, es que retoma la investigación realizada en varias localidades rurales de los estados de Puebla y Tlaxcala, donde se observaron los resultados ya descritos, a saber, abandono de las actividades agropecuarias, falta de interés de las nuevas generaciones por estas actividades, así como cambio de uso de suelo, y apoyos poco efectivos por parte de los gobiernos, entre otros.

Por otra parte, el tema de soberanía alimentaria es muy amplio, por lo que una de las limitantes de este estudio es no abarcar todas las vertientes de este concepto, por ejemplo, la inocuidad de los alimentos, las preferencias culturales en cuanto a alimentación, entre otros. En este trabajo se hizo hincapié en lo que respecta al deterioro de la producción de alimentos, principalmente de autoconsumo en el país, abandono de las actividades agropecuarias comprobado a partir de las modificaciones que ha sufrido la población ocupada en cuanto a sector económico se refiere. La principal debilidad que se considera en esta investigación tiene que ver con sus propias limitaciones. Definitivamente sería mucho más rico presentar estudios sobre los cambios de dieta en las poblaciones rurales derivados de este deterioro de producción de alimentos para autoconsumo, qué alimentos son los que se están sustituyendo y por cuáles, así como estudios sobre la inocuidad de estos. Sin embargo, aunque se han realizado ejercicios en algunas localidades, la extensión del trabajo no permite presentarlos. 


\section{Revista Iberoamericana \\ de las Ciencias Sociales y \\ Humanísticas}

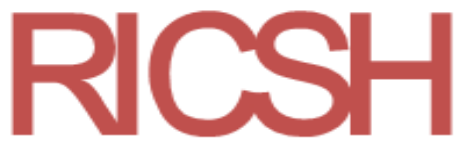

ISSN: $2395-7972$

\section{Referencias}

Acuña, B. O. (2014). Nuevos aportes para el debate en torno a los conceptos de Soberanía Alimentaria y Seguridad Alimentaria. Ponencia presentada en el IX Congreso Sociedades Rurales Latinoamericanas "Diversidades, Contrastes y Alternativas". Ciudad de México, del 6 al 11 de octubre de 2011.

Altieri, M. (1999). Soberanía alimentaria. Acción ecológica, Alerta verde, (80).

Auditoría Superior de la Federación [ASF]. (2018). Informe General Ejecutivo. Cuenta Pública 2016. México: Auditoría Superior de la Federación. Recuperado de asf.gob.mx/Trans/Informes/IR2016ii/documentos/InformeGeneral/IG2016.pdf.

Carmona, J. L. (2008). La actividad agrícola en las localidades rurales en vías de conurbación: El caso de Sta. María Texcalac, Tlaxcala. (tesis de maestría). El Colegio de Tlaxcala. A. C., Tlaxcala.

Carmona, J. L (2013). El deterioro de la producción de alimentos para autoconsumo de las familias rurales campesinas de Atlangatepec, Tlaxcala (Periodo 2009 - 2010). Causales y estrategias de mitigación. (tesis de doctorado en). El Colegio de Tlaxcala. A. C., Tlaxcala.

Carmona, J. L., Paredes, J. A. y Pérez, A. (2017). La Escala Latinoamericana y del Caribe Sobre Seguridad Alimentaria (ELCSA): Una herramienta confiable para medir la carencia por acceso a la alimentación. Revista Iberoamericana de las Ciencias Sociales y Humanísticas, 6(11). 263-286.

Centro de Estudios para el Desarrollo Rural Sustentable y la Soberanía Alimentaria [CEDRSSA]. (2007). Metaevaluación de programas de la SAGARPA dirigidos a productos agrícolas básicos. Resultados generales. México: Centro de Estudios para el Desarrollo Rural Sustentable y la Soberanía Alimentaria. Cámara de Diputados, LX Legislatura.

Foro Mundial sobre Soberanía Alimentaria. (2001). Por el derecho de los pueblos a producir, alimentarse y a ejercer su soberanía alimentaria. Regiones y Desarrollo Sustentable, 3.

García, X. (2003). La soberanía alimentaria: un nuevo paradigma. Barcelona, España: Veterinarios sin Fronteras. Recuperado de http://www.odaalc.org/documentos/1341449192.pdf. 


\section{Revista Iberoamericana \\ de las Ciencias Sociales y \\ Humanísticas}

ISSN: $2395-7972$

Gordillo, G. y Méndez, O. (2013). Seguridad y soberanía alimentaria. (Documento base para discusión). Organización de las Naciones Unidas para la Alimentación y la Agricultura.

II Foro Social Mundial. (2002). Otro mundo es posible. Declaración mexicana de los movimientos sociales. Regiones y Desarrollo Sustentable, 3.

III Foro Social Mundial. (2003). Posición sobre soberanía alimentaria de los pueblos. Nuestro mundo no está en venta, primero está la soberanía alimentaria de los Pueblos. Regiones y Desarrollo Sustentable, 3.

Instituto Nacional de Estadística y Geografía [Inegi]. (1999). Estadísticas históricas de México. Vol. I. México: Instituto Nacional de Estadística y Geografía.

Instituto Nacional de Estadística y Geografía [Inegi]. (2018). Resultados de la encuesta nacional de Ocupación y Empleo. Cifras durante el cuarto trimestre de 2017. Comunicado de prensa núm. 70/18.

Instituto de Seguridad y Servicios Sociales de los Trabajadores del Estado [Issste]. (3 de abril de 2019). México ocupa el primer lugar en obesidad en Latinoamérica. Comunicado de prensa.

La Vía Campesina. (s. f.). La Vía Campesina: La voz de los campesinos y de las campesinas del mundo. La Vía Campesina. Movimiento Campesino Internacional. Recuperado de https://viacampesina.org/es/la-via-campesina-la-voz-las-campesinas-loscampesinos-del-mundo/.

Melgoza, G. (1972). Sociología de la esperanza. (curso de orientación vocacional). Jalapa. Organización de las Naciones Unidas [ONU]. (1948). Declaración Universal de los Derechos Humanos. 10 de diciembre de 1948. Recuperado de https://www.refworld.org.es/docid/47a080e32.html.

Organización de las Naciones Unidas para la Alimentación y la Agricultura [FAO]. (2009). El estado de los mercados de productos básicos agrícolas. Los precios altos de los alimentos y la crisis alimentaria: experiencias y lecciones aprendidas. Roma, Italia: Organización de las Naciones Unidas para la Alimentación y la Agricultura.

Organización de las Naciones Unidas para la Alimentación y la Agricultura [FAO], Fondo Internacional de Desarrollo Agrícola [FIDA], Fondo de las Naciones Unidas para la Infancia [Unicef], Programa Mundial de Alimentos [PMA] y Organización Mundial de la Salud [OMS]. (2018). El estado de la seguridad alimentaria y la nutrición en el 


\section{Revista Iberoamericana \\ de las Ciencias Sociales y \\ Humanísticas}

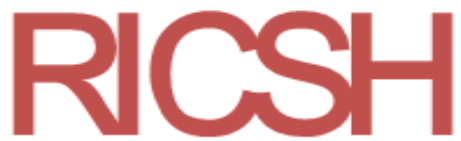

ISSN: $2395-7972$

mundo. Fomentando la resiliencia climática en aras de la seguridad alimentaria y la nutrición. Roma, Italia: Organización de las Naciones Unidas para la Alimentación y la Agricultura.

Ortega, M. y Rivera, M. (2010). Indicadores internacionales de soberanía alimentaria. Nuevas herramientas para una nueva agricultura. Revista Iberoamericana de Economía Ecológica, 14.

Pérez, A., Hernández, C. y Carmona, J. L. (2017). Estrategias de abasto de maíz de los hogares campesinos en el municipio de Atlangatepec, Tlaxcala. Agricultura, Sociedad y Desarrollo, 14(1).

Programa Especial para la Seguridad Alimentaria [PESA]. (2011). Seguridad alimentaria y nutricional. Conceptos básicos (3. ${ }^{\mathrm{a}}$ ed.). Honduras: Programa Especial para la Seguridad Alimentaria.

Ramírez, E. (2005). Transnacionales arrasan el agro. Revista Contralínea. Recuperado de http://contralinea.com.mx/archivo/2005/diciembre/htm/trasnacionales_arrasan_agro. htm.

Ramírez, E. (2008). Calderón cede soberanía alimentaria. Revista Contralínea, 7(104). Recuperado de https://www.contralinea.com.mx/archivo/2008/junio2/htm/calderoncede-soberania-alimentaria.htm.

Román, S. I. y Hernández, S. (2010). Seguridad alimentaria en el municipio de Oxchuc, Chiapas. Agricultura, Sociedad y Desarrollo, 7(1), 71-79.

Rosset, P. (2004). Reclamo mundial del movimiento campesino. Ecofronteras, 18(51), 8-11. Recuperado de http://revistas.ecosur.mx/ecofronteras/index.php/eco/article/view/1056/1029.

Rubio, B (2008). De la crisis hegemónica y financiera a la crisis alimentaria. Impacto sobre el campo mexicano. Argumentos, 21(57).

Salinas, A. (1990). Notas sobre la modernización industrial. Momento Económico, (50).

Secretaría del Trabajo y Previsión Social [STPS]. (2020). Informe laboral febrero 2020. Ciudad de México, México: Secretaría del Trabajo y Previsión Social.

Sistema de Información Agroalimentaria y Pesquera (SIAP). (2017). Balanzas disponibilidad -consumo de productos agrícolas, disponible en www.siap.gob.mx/balanzadisponibilidad-consumo/ consultado el 23 de enero 2020 
Revista Iberoamericana

de las Ciencias Sociales y

Humanísticas

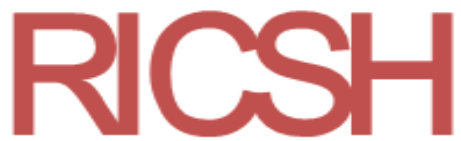

ISSN: 2395 - 7972

Torres, F. y Aguilar, T. (2006). Aspectos externos de la vulnerabilidad alimentaria de México. En Torres, F. (coord.), Seguridad alimentaria: seguridad nacional. México: Plaza y Valdés Editores. 
Revista Iberoamericana

de las Ciencias Sociales y

Humanísticas

ISSN: $2395-7972$

\begin{tabular}{|l|l|}
\hline Rol de Contribución & Autor (es) \\
\hline Conceptualización & José Luis Carmona Silva \\
\hline Metodología & José Luis Carmona Silva \\
\hline Software & No aplica \\
\hline Validación & José Luis Carmona Silva \\
\hline Análisis Formal & José Luis Carmona Silva \\
\hline Investigación & José Luis Carmona Silva \\
\hline Recursos & $\begin{array}{l}\text { José Luis Carmona Silva (Principal). Lizbeth Sánchez Flores } \\
\text { (Apoyo) Ramón Sebastián Acle Mena (Apoyo) }\end{array}$ \\
\hline Curación de datos & No aplica \\
\hline $\begin{array}{l}\text { Escritura - Preparación del } \\
\text { borrador original }\end{array}$ & $\begin{array}{l}\text { José Luis Carmona Silva (Principal). Lizbeth Sánchez Flores } \\
\text { (Apoyo) Ramón Sebastián Acle Mena (Apoyo) }\end{array}$ \\
\hline $\begin{array}{l}\text { Escritura - Revisión y } \\
\text { edición }\end{array}$ & $\begin{array}{l}\text { José Luis Carmona Silva (Principal). Lizbeth Sánchez Flores } \\
\text { (Apoyo) Ramón Sebastián Acle Mena (Apoyo) }\end{array}$ \\
\hline Visualización & $\begin{array}{l}\text { José Luis Carmona Silva (Principal). Lizbeth Sánchez Flores } \\
\text { (Apoyo) Ramón Sebastián Acle Mena (Apoyo) }\end{array}$ \\
\hline Supervisión & José Luis Carmona Silva \\
\hline Administración de & José Luis Carmona Silva \\
\hline Adquisición de fondos & Ramón Sebastián Acle Mena (Apoyo) \\
\hline
\end{tabular}

